\title{
Surface Features of TIG Melting Coated CP-titanium
}

\author{
S.A. Adeleke ${ }^{1, a}$ and M.A. Maleque ${ }^{1}$ \\ ${ }^{1}$ Advanced Materials and Surface Engineering Research Unit \\ Department of Manufacturing and Materials Engineering \\ International Islamic University Malaysia, P.O. Box 10, 50728, Kuala Lumpur, Malaysia \\ adelekeshakiru@gmail.com, maleque@iium.edu.my
}

\section{Keywords: TIG; Glazing speed; CP-titanium; Fe-C-Si; TiC}

\begin{abstract}
Tungsten inert gas (TIG) melting process is increasingly find successful application in many aspects of engineering part components. In this study, TIG melting of Fe-based coating has been successfully developed by precoated iron, carbon and silicon (Fe-C-Si) powders on commercial purity titanium (CP-titanium) surface under three different glazing speeds such as 1.0 $\mathrm{mm} / \mathrm{s}, 1.5 \mathrm{~mm} / \mathrm{s}$ and $2.0 \mathrm{~mm} / \mathrm{s}$ and constant energy input of $1350 \mathrm{~J} / \mathrm{mm}$ in an argon gas environment. The effects of glazing speeds on the surface topography, melt geometry, microstructure and hardness were investigated. Rippling marks were found on all the track surfaces which portends that good solidification of the molten melt pool had taken place near the base metal. The melt pool layers consisted of higher population of dendrites and the population were found to decrease with increasing glazing speeds. The resolidified surface layer of the dendrites developed hardness 3 to 4 times higher than that of the base material. According to the enthalpy reactions due to formation of titanium carbide, silicon carbide and iron carbide during TIG melting of Fe-C-Si coated titanium surface are considered to be responsible for larger melt depth. These results showed that surface properties of CP-titanium can be enhanced with Fe-C-Si using TIG melting process.
\end{abstract}

\section{Introduction}

Advances in technological development of high technological fields such as aerospace, power plant, chemical plant and marine industries has given rise to constantly increasing demands for material surfaces that can withstand high tribological loads. Owing to this several surface coating techniques have been developed. Among these coating techniques, TIG coating is the versatile and most common method for surface alloying and surface modification of engineering part component. Over the last decades, several studies have been conducted on the gas tungsten inert gas process to modify the properties of titanium and its alloy $[1,2]$. Since then a significant improvement has been recorded in terms of surface structure, hardness and wear resistance [1]. Tungsten inert gas modification is a process by which alloy powders of desirable composition are fused onto metallic substrate (titanium or low alloy steel) by melting to form a dense coating with good metallurgical bonding to the substrate. The development of surface hard layer by incorporating Fe-based alloy into molten alloy pool has been researched upon in order to improve the surface structure of material [3]. The important features offered by this iron based alloy include high hardness, high wear resistance and good wettability. These outstanding features make them promising alloying materials for protective hard coating application. In the study conducted by Sabet et al. [3] on AISI mild steel by melting Fe-Cr-C powder using TIG technique. A significant improvement was recorded for both hardness and wear resistance. Azimi and Shamanian [4] investigated the effect of silicon content on St52 steel by studying the microstructure and properties of $\mathrm{Fe}-\mathrm{Cr}-\mathrm{C}$ hardfacing alloys. They reported that the presence of silicon in the $\mathrm{Fe}-\mathrm{Cr}-\mathrm{C}$ powder gave rise to increase in hardness and wear resistance. Tungsten inert gas surface alloying of SAE 1020 steel was carried out by Eroglu and Ozdemir [5] using graphite, chromium and high-carbon ferro chromium powders. A high hardness and wear resistance was obtained which was attributed to higher volume fraction of carbides in the microstructure. Thus, TIG has provided a remarkable enhancement on the surface properties of engineering material without impairing the bulk properties. Consequently, many researchers are focusing on surface wear resistance coating material and are using various 
techniques to improve the surface quality. This paper introduces Fe-C-Si ternary powder mixtures on CP-titanium surface using tungsten inert gas melting process. The surface topography, melt geometry, microstructure and microhardness are presented.

\section{Experimental details}

CP-titanium specimen with $50 \times 40 \times 10 \mathrm{~mm}$ dimensions were used as the substrate. The surfaces of specimen were prepared by surface grinding to eliminate any contaminants before being rinsed with acetone. The coating material is a blended powder mixture of $\mathrm{Fe}, \mathrm{C}$ and $\mathrm{Si}$ with a weight ratio of 85: 10:5 (in wt. \%) respectively. The blended powder weighed at $1 \mathrm{mg} / \mathrm{mm}^{2}$ was mixed with PVA solution before it was evenly spread on the titanium substrate and oven dried at $80{ }^{\circ} \mathrm{C}$ for 1 hour to remove excessive moisture. Single track were produced at constant energy input of $1350 \mathrm{~J} / \mathrm{mm}$ with three different glazing speeds such as $1.0 \mathrm{~mm} / \mathrm{s}, 1.5 \mathrm{~mm} / \mathrm{s}$ and $2 \mathrm{~mm} / \mathrm{s}$ using TIG 165 welding machine with $3.2 \mathrm{~mm}$ in diameter of tungsten thoriated electrode. The arc energy input was calculated using a simple mathematical expression which was also used in other work [6]. Detailed information on the experimental procedures can be found in literature [2].

\section{Results and discussion}

Surface topography. Fig.1 shows the surface topographies of all the tracks produced under different glazing speeds and energy input of $1350 \mathrm{~J} / \mathrm{mm}$. The surface structures of the track produced at different glazing speeds revealed that all the surfaces are fairly smooth with defect free surfaces. The surface smoothness is considered to be related to the fluidity of the melt. Surface modification using a lowest glazing speed produced a melt with higher viscous and on rapid solidification there is less time for flow to occur resulting to smoother surface. Prominent rippling marks were also found to form in two different directions which are along and perpendicular to the electrode traversing direction. The radial rippling marks along the electrode traversing direction are the evidence of which solidification of molten melt pool took place near the base metal and lastly to solidify near the arc source. The freezing of the liquid melt containing wavy surface is considered to be responsible for rippling marks on the track surface [7].

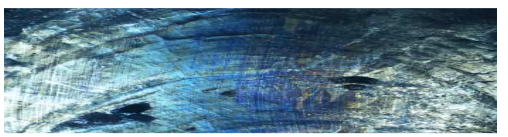

(a)

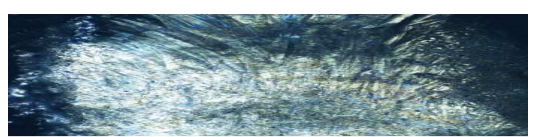

(b)

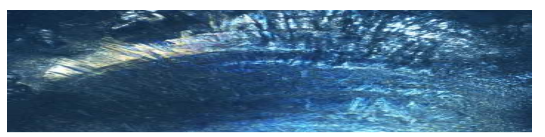

(c)

Fig. 1 Topography of the track surfaces produced at different glazing speeds and energy input 1350 $\mathrm{J} / \mathrm{mm}$ (a) $1 \mathrm{~mm} / \mathrm{s}$, (b) $1.5 \mathrm{~mm} / \mathrm{s}$ and (c) $2 \mathrm{~mm} / \mathrm{s}$

Melt geometry and configuration. The melt width and depth of the transverse sections for the tracks produced with different TIG glazing speeds are given in Table 1 . The results in Table 1 shows that the melt layer depth produced with lowest glazing speed is 1.4 to 1.6 times greater compared to the melt depths obtained when processed with higher speeds. The formation of larger melt depth is believed to be directly related to enthalpy of carbides formation in the melt pool layer. The increased solubility of carbon in pure titanium at lowest speed assisted the greater dissolution of powder preplaced mixtures in titanium melt matrix. This explanation is also supported by metallographic evidence with a higher dendritic structure in the melt pool layer shown in Fig 3 (a).

Table 1 Melt depth and width of tracks produced under different TIG glazing speeds

\begin{tabular}{|c|c|c|c|}
\hline Energy input [J/mm] & TIG glazing speed [mm/s] & Melt depth [mm] & Melt width [mm] \\
\hline \multirow{3}{*}{1350} & 1.0 & 2.05 & 7.52 \\
\cline { 2 - 4 } & 1.5 & 1.43 & 6.08 \\
\cline { 2 - 4 } & 2.0 & 1.21 & 5.56 \\
\hline
\end{tabular}


At higher glazing speeds, the melt depth and width of the track decrease. Processing with higher glazing speeds, the carbides concentration decreases resulting in lesser amount of thermal energy and shallower melt pool size. The melt pool size has been reported to depend on several parameters such as glazing speed, operating current and arc length [8]. Fig. 2 shows the melt cross-sections of the tracks produced with three different glazing speeds and energy input of $1350 \mathrm{~J} / \mathrm{mm}$. The resolidified melt tracks were found to be irregularly in shape. The non-uniform pattern of the melt pool layer can be attributed to Maragoni force convection flow of the liquid in the melt. This type of flow is due to flow pattern of carbides in the melt and their position changes with the precipitation of carbides in the melt. A similar melt pool layer has also been reported when scanning was performed under a reactive environment by $\mathrm{Hu}$ et al. [9].

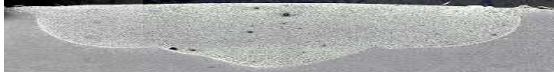

(a)

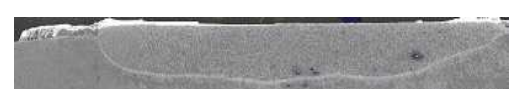

(b)

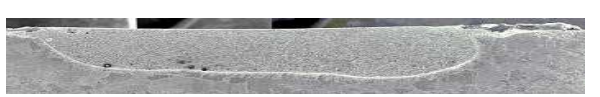

(c)

Fig.2 SEM melts cross-section profiles produced at $1350 \mathrm{~J} / \mathrm{mm}$ and three different glazing speeds (a) $1.0 \mathrm{~mm} / \mathrm{s}$, (b) $1.5 \mathrm{~mm} / \mathrm{s}$ and (c) $2.0 \mathrm{~mm} / \mathrm{s}$

Microstructures. Fig. 3 shows the microstructures developed on CP-titanium surface with three different glazing speeds and energy input of $1350 \mathrm{~J} / \mathrm{mm}$. At low glazing speed, the whole melt depth consisted of dendrites (Fig. 3(a)). The population of dendrites was found to decrease with increasing glazing speeds. This is due to increase in available heat at a low speed. The amount of carbon is believed to have influenced the population of dendrites and the concentration in the melt. At this given speed, higher diffusivity of carbon in the melt is thought to produce a greater concentration of carbon in the melt resulting higher population of dendrites. However, increasing the glazing speed would have the opposite effect due to insufficient of heat input at higher speeds. Glazing with high speed produces low energy input with less amount of dissolution of powder preplaced mixtures in the melt [8]. Processing with highest speed produced pores in the melt microstructure. With increasing glazing speed, the viscosity of the melt reduces and caused difficulty for the excess gas to escape from the liquid melt during solidification. This has been reported as the cause of pore formation in the melt matrix area [7]. The elemental analysis of this dendritic structure (Fig. 3 (d) gave mainly $\mathrm{Ti}$ and $\mathrm{C}$. The strong affinity of carbon to titanium in the melt is significantly greater compared to $\mathrm{Fe}$ and $\mathrm{Si}$. The X-ray patterns from the surface of the sample processed with low glazing speed (Fig. 4) showed that the melt structure contains titanium carbided $(\mathrm{TiC})$, silicon carbide $(\mathrm{SiC})$ and iron carbide $\left(\mathrm{Fe}_{3} \mathrm{C}\right)$ phases. The dendrites are identified as TiC.

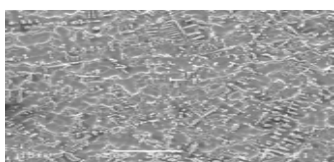

(a)

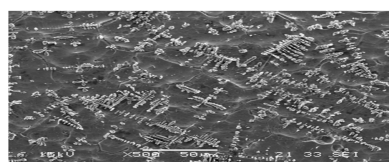

(b)

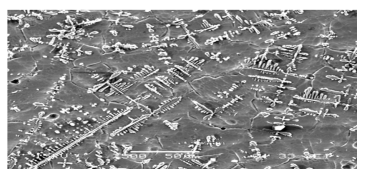

(c)

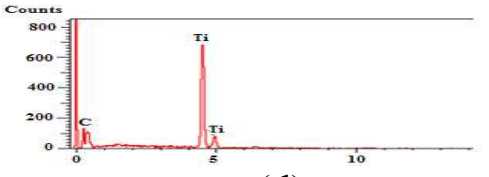

(d)

Fig. 3 Microstructure developed at different glazing speeds (a) $1.0 \mathrm{~mm} / \mathrm{s}$, (b) $1.5 \mathrm{~mm} / \mathrm{s}$, (c) 2.0 $\mathrm{mm} / \mathrm{s}$ and (d) Elemental analysis within the dendrites.

Microhardness. The surface hardness of the developed layer processed under different glazing speeds is depicted in Fig. 4. This figure shows that processing at low speed produced a very high surface hardness of about $770 \mathrm{HV}_{0.5} \mathrm{kgf}$ which is 3.5 to 4 times higher than the base hardness (200 HV $0.5 \mathrm{kgf})$. With the highest glazing speed, the maximum hardness developed was reduced to 565 HV $0.5 \mathrm{kgf}$ with comparatively shallower hardness profile. It is to be noted that this glazing speed produced fewer pores in the melt microstructure. 

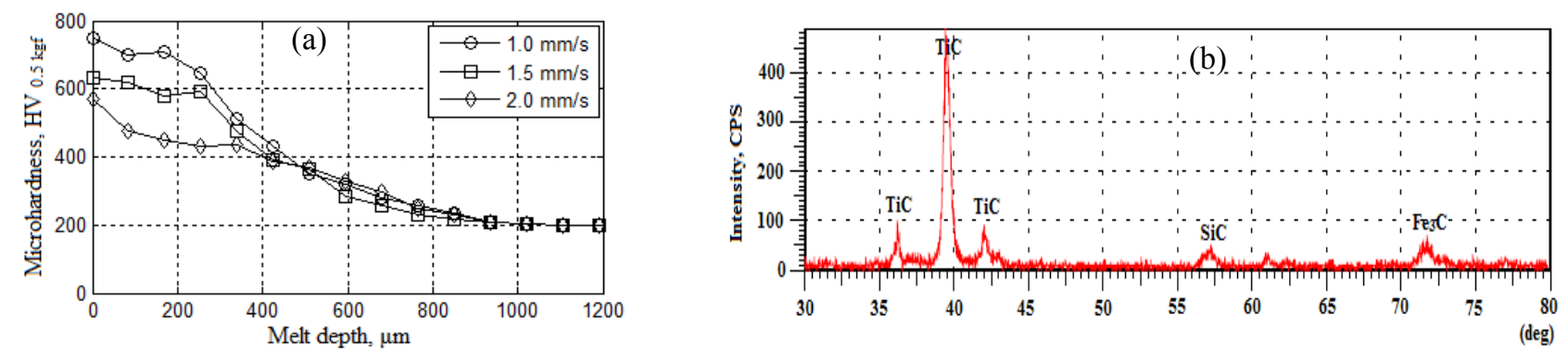

Fig 4. (a) Microhardness of the processed layer (b) XRD pattern obtained from the surface ofl $\mathrm{mm} / \mathrm{s}$

\section{Conclusion}

TIG melting of commercial purity titanium with a preplaced $85 \mathrm{Fe} 10 \mathrm{C} 5 \mathrm{Si}$ layer has been successfully carried out. Coating produced by TIG cladding with premixed powder showed rippling marks on all the track surfaces with deeper melt depth. The molten region produced for the three different glazing speeds at energy input of $1350 \mathrm{~J} / \mathrm{mm}$ dissolved Fe-C-Si particles and the resolidified melt layer consisted of higher population of dendrites. The population of dendrites was found to decrease with increasing glazing speeds. The maximum hardness developed was found to be $770 \mathrm{HV}_{0.5 \mathrm{kgf}}$ which was 3 to 4 times the base hardness $\left(200 \mathrm{HV}_{0.5 \mathrm{kgf}}\right)$.

\section{Acknowledgement}

The authors would like to thank the Research Management Center (RMC) of International Islamic University Malaysia for their parts in funding this project under grant RMGS 1212-007-0020.

\section{References}

[1] A. Monfrared, A.H. Kokabi and S. Asgari: Journal of Materials Chemistry and Physics Vol. 137 (2013), p. 959-966.

[2] S.A. Adeleke and M.A. Maleque: Accepted for publication in Advanced Materials and Research (2014).

[3] H. Sabet, Sh. Khierandish and Sh. Mirdamadi: Triobology letters Vol. 44 (2011), p. 237245.

[4] G. Azimi and M. Shamanian: Journal of Materials Science Vol. 45 (2010) p. 842-849.

[5] M. Eroğlu and N. Özdemir: Surface and Coatings Technology Vol. 154 (2002), p. 209-217.

[6] K.E. Easterling: Introduction to physical metallurgy of welding: Butterworth-heinemann, London, 1992.

[7] S. Mridha: Journal of Materials Processing Technology Vol. 168 (2005) p. 471-477.

[8] S. Kou: Heat flow in welding. Welding Metallurgy, Second Edition (2003), p. 37-64.

[9] C. Hu, H. Xin and T.N. Baker: Journal of Materials Science, Vol. 30 (1995), p. 5985-5990, 1995. 